\title{
Service Robots for Hospitals: A Case Study of Transportation Tasks in a Hospital
}

Özkil, Ali Gürcan; Fan, Zhun; Dawids, Steen; Klæstrup Kristensen, Jens; Christensen, Kim Hardam; Aanæs, Henrik

\section{Published in:}

Proceesings of 2009 IEEE International Conference on Automation and Logistics

Link to article, DOI:

10.1109/ICAL.2009.5262912

Publication date:

2009

Document Version

Publisher's PDF, also known as Version of record

Link back to DTU Orbit

Citation (APA):

Özkil, A. G., Fan, Z., Dawids, S., Klæstrup Kristensen, J., Christensen, K. H., \& Aanæs, H. (2009). Service Robots for Hospitals: A Case Study of Transportation Tasks in a Hospital. In Proceesings of 2009 IEEE International Conference on Automation and Logistics IEEE. https://doi.org/10.1109/ICAL.2009.5262912

\section{General rights}

Copyright and moral rights for the publications made accessible in the public portal are retained by the authors and/or other copyright owners and it is a condition of accessing publications that users recognise and abide by the legal requirements associated with these rights.

- Users may download and print one copy of any publication from the public portal for the purpose of private study or research.

- You may not further distribute the material or use it for any profit-making activity or commercial gain

- You may freely distribute the URL identifying the publication in the public portal 


\section{Service Robots for Hospitals: A Case Study of Transportation Tasks in a Hospital}

\author{
Ali Gürcan Özkil, Zhun Fan and \\ Steen Dawids \\ Department of Management Engineering \\ Technical University of Denmark \\ 426 Produktions Torvet, 2800, Lyngby, \\ Denmark \\ (alio, zhfa)@ man.dtu.dk
}

\author{
Henrik Aanæs \\ Department of Informatics and Mathematical \\ Modeling \\ Technical University of Denmark \\ 321 Richard Pedersen Plads, 2800,Lyngby \\ Denmark \\ haa@imm.dtu.dk
}

Jens Klæstrup Kristensen and Kim Hardam Christensen

Welding \& Production

Innovation

Force Technology

Park Alle 345, 2605, Brøndby,

Denmark

(jek, kmc)@force.dk

\begin{abstract}
In this paper, the need for automated transportation systems for hospitals is investigated. Among other alternatives, mobile robots stand out as the most prominent means of automation of transportation tasks in hospitals.

Existing transportation routines of a hospital are analyzed in order to verify the need for automation and identify possible areas of improvement. The analysis shows that most of the existing transportation is carried out manually, and hospitals can greatly benefit from automated transportation. Based on the results of the analysis, three alternatives are derived for implementing mobile service robots for transportation tasks in hospitals.
\end{abstract}

\section{Index Terms - hospital logistics, mobile robots, $A G V$}

\section{INTRODUCTION}

In this paper, it is aimed to analyze the transportation routines of a hospital, in order to understand needs for designing mobile robotic transportation systems and identify possible types of transportation tasks that can be improved by automation. As a result of the analysis, three strategies are developed and discussed for using autonomous mobile robots at hospitals for transportation: Adapting to existing transportation system, partial reconfiguration of transportation system and reconstruction of the whole system.

The paper is organized as follows. In the second section, the need for transportation automation in hospitals is elaborated and existing automation systems are presented. In the third section, Bispebjerg Hospital, where the analyses of the transportation tasks made upon is described in detail. In the fourth section, findings of the paper are discussed, and in the last section, conclusions are presented.

\section{BACKGROUND}

\section{A. Need for automation in hospital logistics}

Hospitals are one of the vital organs of the modern society. Demographical factors, such as increasing elderly population, bring up the need for reviewing healthcare services to improve hospital operations and their efficiency and effectiveness.

The primary service provided by a hospital is patient care. In order to able to supply this service, there are a number of support services that needs to be taken care of in the hospital. Even though most of these services are invisible to patients, they have a considerable effect on how patients experience their visit to the hospital.

One of the major and usually underestimated support services in hospitals is the logistics. Main task of a hospital logistics service is to organize and maintain the material flow in the hospital. A vast variety of materials are essentially needed in a hospital, which often result in complex transportation systems and tangled flow of materials.

There is a growing interest in automation of logistics in hospitals. The main motivation behind is to reduce operational costs; nearly $\% 30$ of hospital expenses is resulting from logistics activities [1]. Statistics also show that the number of hospital patients is increasing in western countries such as Denmark [2,3], which substantially increase the load of supporting logistic functions. Finally, variety of materials and equipment that are being used in hospitals is expanding. New supplies and equipments are being developed increasingly, and one-time use, disposable items are being more common. As a result, the volume of transportation expands substantially; there are more materials to be transported, and they need to be transported more frequently.

Transportation capacities of can also be improved by automation. Manual hospital transportation tasks are usually bounded with the limitations of available human work power. Routes, volumes, weights and frequencies are planned according to available means of transportation framework and personnel. An automated system, on the other hand, can yield to a much flexible transportation plan. Routes can be optimized, and more frequent deliveries can be planned for both night and day time. The speed of response to inquiries can also be improved if tracking and inventory systems and transportation system is tightly integrated.

Finally, effectiveness of everyday processes in hospitals can be improved. Staff can save considerable amounts of times, which in turn can be allocated to more patient related tasks. Therefore the quality of the service provided to the patient can be improved. 
B. Review of the automation systems used in hospital

From certain aspects, hospitals are similar to manufacturing facilities; therefore many automation applications are adapted from these environments.

Pneumatic tube systems are one of the most commonly used delivery systems in hospitals. They consist of a tube network that links different units in the hospitals. The cargo is placed in special containers, fed to the tube system at stations and moved by pneumatic forces created by the fans and pumps connected to tube network. It is usually used for small sized cargo; such as papers, specimens or pharmaceuticals.

Track and conveyor systems are also common in hospitals for delivering relatively larger loads. Rails or conveyor belts are installed in horizontal or vertical configurations and materials are transported between floors and hospital units using self-contained lifting and dragging systems.

An alternative to such systems, which is also the focus of this study, are mobile robots. Using robotic vehicles for transportation has been of a great interest in manufacturing sites for decades, where the environment often needed to be modified. In the last decade, these systems also became popular in hospitals as localization techniques are more advanced, and range sensors are faster and more precise; which makes it possible to implement such systems with minor modifications in environments.

Helpmate was one of the pioneer implementations of automated robotic hospital transportation systems [4]. It was designed for transporting small sized cargo between departments, and it was able to autonomously navigate inside the hospitals, take elevators and avoid obstacles. Care-o-bot was developed to provide physical support to people requiring mobility and tele-presence capabilities for remote inspection, in addition to navigation capabilities [5]. I-Merc was introduced in [6], as a new and automated method of distributing meals in hospitals. In [7], a system that consists of mobile robots and automated pick-up/delivery stations is introduced. Automated stations enabled operation without the need of human loading and unloading at delivery points.

Commercial applications have also started to emerge in recent years. TUG [8] robot commercialized by Aethon, is a robotic system consisted of a tugging vehicle and specially designed charts to which the robot can be connected to. The system can navigate autonomously, and it also provides a system for tracking cargo using RFID technology. Speciminder [9] is another commercial robot, which is specifically designed for distributing lab specimens throughout the facilities. It has similar autonomous navigation capabilities to TUG, but the cargo container is directly placed on top of the robot. Transcar [10] developed by Swisslog is also a similar system, which consist of a laser guided low-height vehicle that can go under wheel supported cargo carts (with loads up to $450 \mathrm{~kg}$ ), lift them up, and transport to designations that are written to the RFID tags on the carts. Lastly, FMC Technologies developed ATLIS[11], based on their AGV platform that was already being used in manufacturing plants.
It is very similar to Transcar, but it is larger and has greater payload $(680 \mathrm{~kg})$.

It is notable that most of the systems above are successors or derivations of applications existed in other domains.

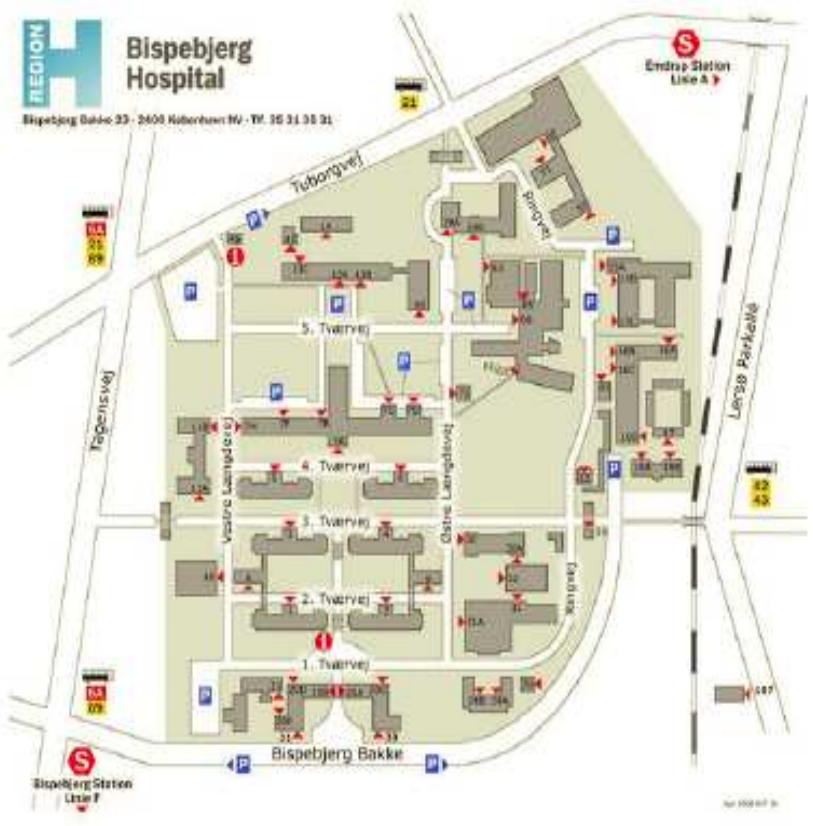

Figure 1, Map of the Bispebjerg Hospital

\section{ANALYSIS OF TRANSPORTATIONS IN A HOSPITAL}

In this section presents the analysis of the current transportation situation in a hospital, and it is believed that a careful investigation of the transportation routines is needed to be able to design efficient robots and achieve efficiencies in a more global scale.

\section{A. Description of the Bispebjerg Hospital}

Bispebjerg Hospital is located in the Northwest quarter of Copenhagen, Denmark. Due to its size and architecture, it represents a typical mid-sized European hospital. It serves to a population of 255.000 inhabitants [6], with around 500 available beds and 3000 staff.

Bispebjerg Hospital was built in 1913, where different units were physically separated in a campus like architecture. An underground tunnel network connects most of the buildings. (Figure 1)

\section{B. Description of internal transportation tasks:}

The transportation tasks inside the hospital are classified according to the originated sources of the supplies. An overall view of the transportation tasks is given in table 1 .

The tasks are described as follows:

\section{1) Pharmaceutical supplies}

Each hospital unit has a room for stocking regularly used medicines. A pharmacist is associated to a number of medicine 
storage rooms, whom each day checks the status of supply and orders new medicine from the central pharmacy. Unit nurses can inquire for extra medicine, using an order book. The pharmacist has the authority to register and send these orders.

Table 1, Summary of transportation tasks

\begin{tabular}{|l|c|c|}
\hline Task & Personnel involved & Ilours/Week \\
\hline $\begin{array}{l}\text { Medicine } \\
\text { Transport }\end{array}$ & Porter (2) & 50,4 \\
\hline $\begin{array}{l}\text { Mail } \\
\text { Delivery }\end{array}$ & Hospital Employee (4) & 107,1 \\
\hline $\begin{array}{l}\text { Transports to } \\
\text { Unit } \\
\text { Storages }\end{array}$ & Porter (1) & 27 \\
\hline $\begin{array}{l}\text { Transports to } \\
\text { Sterile } \\
\text { Cabinets }\end{array}$ & Hospital Fmployee (2) & 69 \\
\hline $\begin{array}{l}\text { Food } \\
\text { Transport }\end{array}$ & Porter (5) & 98 \\
\hline $\begin{array}{l}\text { Transports } \\
\text { from central } \\
\text { supply }\end{array}$ & Porter (2) & 51,8 \\
\hline $\begin{array}{l}\text { Empty beds } \\
\text { Transport of } \\
\text { clothes }\end{array}$ & Porter (3-4) & 113,4 \\
\hline $\begin{array}{l}\text { Waste } \\
\text { Collection }\end{array}$ & Porter (4) & 130 \\
\hline
\end{tabular}

There is a central pharmaceutical storage outside the hospital, which serves to a number of hospitals in the region. But inside the hospital, the system is distributed, so there is not a central unit for storing pharmaceuticals. Each day, the ordered medicine from the central storage is sent to the hospital in sealed boxes. These boxes are received by two porters, and then the medicine is distributed to various hospital units. At units, sealed packages are delivered in exchange of the signature of the responsible pharmacist or the head nurse of the unit. Only the pharmacist has the right to break the seal and add the medicines to the unit's inventory.
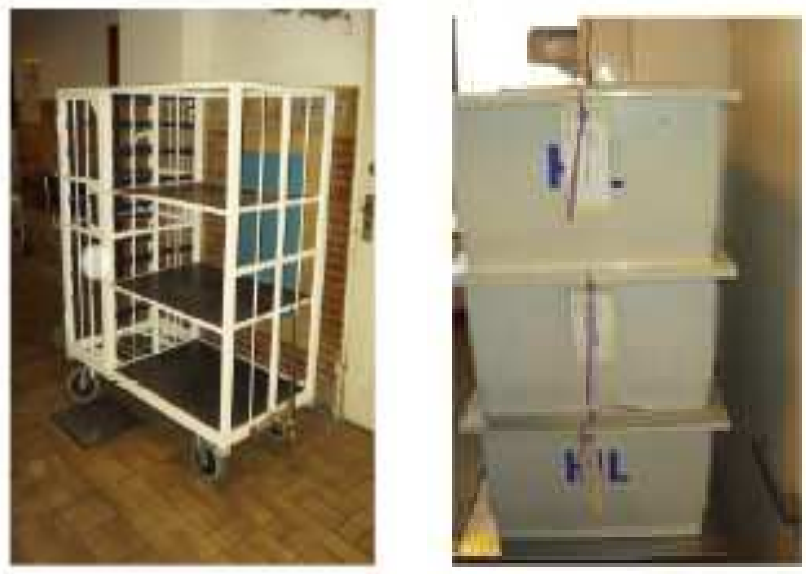

Figure 2, Carts and sealed boxes for delivering pharmaceutical supplies
Pharmaceutical waste is consisted of leftover or expired medicine. These medicines are separated and returned back to the central pharmaceutical storage in the same way new medicine arrives. Patient medicine is regarded as clinical waste and disposed into yellow contaminated waste boxes, in compliance with bio-hazardous waste disposal regulations.

\section{2) Internal post office}

The hospital has an internal post office located close to the administrative units. The internal post office is mainly responsible from distribution of external mail received from the national postal service, collection and distribution of internal mail, and collection and dissemination of mail going out of the hospital. Additionally, the internal post office is the support unit for miscellaneous urgent delivery tasks, such as transportation of medical records, test samples or results, or blood units.

There are five specified routes for mail delivery from the post office to hospital units. in each unit, the postal worker delivers the new mail and collects the mail from the outgoing box, and brings it back to the post office. Collected mail is sorted at the post office together with the external received mail, and the same routine is repeated two or three times a day, depending on the mail traffic. It is noteworthy that the mail delivery to the administrative units is done only once per day, because it is very time consuming due to the number of post boxes to visit ( approximately $\% 25$ of the whole distribution routine).

The general tasks of the internal post office are handled by nine postal workers. In each round of mail delivery, four postal workers are active. It takes around 1 hour and 15 minutes to complete a round and return back to the post office. For the urgent delivery tasks, at least one person is kept on stand-by at the post office.

\section{3) Sterile production}

At the hospital, there are a total of 72 sterile cabinets in various units. These cabinets are used for keeping various sterile tools needed for the daily work. to make sure that the cabinets are equipped with the necessary content, the hospital has a department responsible for maintaining the stock and refilling of these cabinets. The department is also responsible from collecting sterilizing and packing the reusable equipment.

Everyday, each of these cabinets are visited by two porters and needed tools are recorded. in a second round same employees revisit the cabinets where new supplies are needed. Depending on the unit, each cabinet is refilled one to three times a week.

Every morning, a porter collects used tools. Porter visits hospital's units, collects the tools in a large cart, and returns them back to sterile production unit for cleaning and resterilizing.

\section{4) Central sterile products storage}

The sterile products storage is responsible from storing both sterile and non-sterile single use products. 
Ordering of non-sterile products is done through an internal online ordering system automatically, so that the storage keeps a minimum amount of supplies. Single use products are handled in the same way as sterile tools coming from sterile production unit, and are kept in the same sterile cabinets. These products are delivered together with the sterile tools, and then disposed to contaminated waste boxes.

\section{5) Kitchen}

Each hospital unit order food needed using the same ordering system as sterile products storage. The orders are processed in the hospital kitchen and food is distributed to units in two rounds: at $7 \mathrm{AM}$ for the breakfast and at 11:30 $\mathrm{AM}$ for lunch and dinner. Food is delivered to units in special carts with heating and refrigeration (Figure 3). Each unit is responsible from the internal distribution of the food and supplement of tableware. One hour after the delivery, the empty carts are collected by the same porter that makes the delivery. Apart from meals, kitchen also supplies groceries such as bread, snacks and drinks to units. Each unit consumes a cart of groceries per week, and everyday, six to nine carts of groceries are distributed. Bottles are collected from hospital units and returned to the kitchen storage.

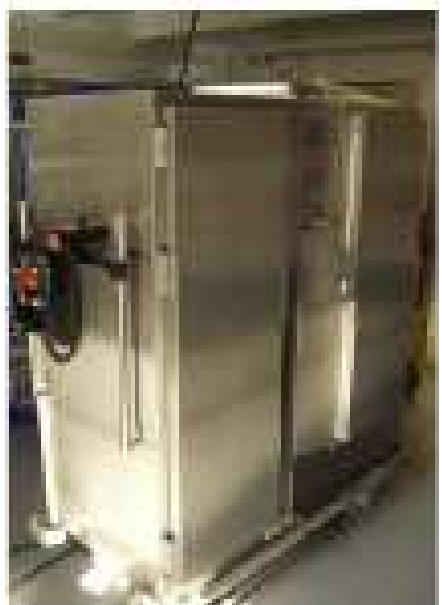

Figure 3, Food cart with heating and cooling

\section{6) Central storage}

Central storage is the main storage facility of the hospital. Currently 1296 stock articles are handled by the central storage.

Hospital units place their orders weekly, using an online ordering system and receive their orders on a specific day of the week. Three carts are available for transportation of good from the central storage. There are rounds throughout the day, and in each round there are 3 to 5 stops. Goods are only going out of the central storage; therefore each cart comes back empty at the end of the round.

\section{7) Bed maintenance}

Each time a bed patient is discharged, the used bed is sent to the bed maintenance central for cleaning. During the first half of 2008, an average of 2700 beds were processed per month.

Used beds are usually collected by the department's three porters, or sometimes sent directly from the unit the patient is discharged. When a bed arrives, sheet, cover, quilt and pillow is removed and delivered to the laundry central. Each bed is identified with a barcode, and based on the history of its circulation; the bed undergoes a certain cleaning routine. Cleaned beds are remade using clean linens, and kept in a storage zone, as seen in Figure 4, which can store up to 80 beds.

\section{8) Laundry central}

Laundry central in the Bispebjerg hospital serves to a number of hospitals in the region. In total, $\% 20$ of the production is allocated to Bispebjerg.

Everyday, $30-45$ carts of clean clothes are distributed, whereas 25-30 carts of dirty clothes are collected in the hospital. Personnel uniforms are handled separately from the other cloths, where the staff can pick up clean uniforms from special cloth boxes.

One unit employee goes rounds at 60 different storage rooms of the hospital and estimates the needed supplies. Based on these estimations, clean cloths are delivered to these rooms and dirty ones are collected subsequently. Dirty cloths weigh \%10-12 higher than the clean cloths per unit cargo.

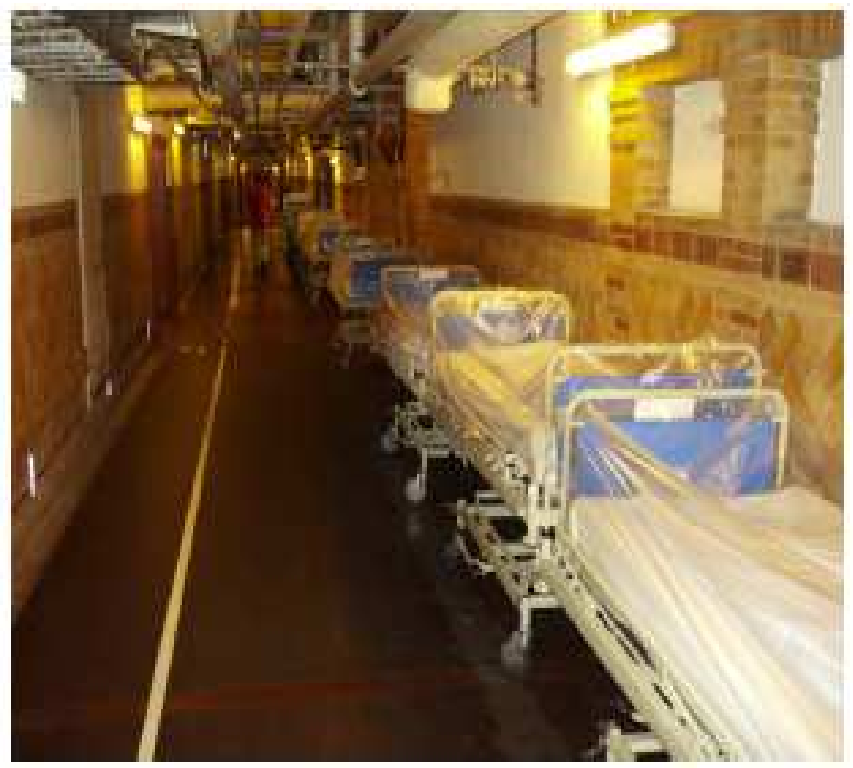

Figure 4, Clean beds are kept in the buffer zone

\section{9) Refuse disposal / renovation}

Refuse disposal unit is responsible from gathering and sorting hospital waste. There are several types of waste being collected. These types and corresponding amounts of waste collected in 2007 are given in table 2.

There are certain regulations on disposal of waste in hospitals, as mentioned in the pharmaceutical supplies section. Each hospital unit is responsible from sorting their own waste. 
Clinical waste must be kept in sealed containers in disposal rooms that are located in each floor or unit of the hospital. Most of the waste generated in the hospital is stored in disposal rooms, but some of the general-purpose waste is disposed to garbage chutes.

Table 1, Types and amounts of waste collected in 2007

\begin{tabular}{|l|c|}
\hline Category & Weight (in tonnes) \\
\hline Refuse & 813,78 \\
\hline Clinical waste & 46,64 \\
\hline Cardboard (recycled) & 48,14 \\
\hline Paper (recycled) & 45,65 \\
\hline Bulky refuse & 82,52 \\
\hline Construction waste & 28,12 \\
\hline Glass & 7,37 \\
\hline Electronics & 3,21 \\
\hline Refrigerants & 12 \\
\hline Iron and metal & 10,86 \\
\hline
\end{tabular}

\section{DISCUSSION}

The analysis clearly shows that the transportation system in the hospital is very complex. Some of the sources of the complexity are identified as the different sources of material flow, different time constraints on distribution routines, work regulations of the personnel and transportation equipment being used.

Based on the findings, three alternatives are devised for the implementation of autonomous robots in transportation systems in hospitals:

1. Adaptation to the existing system: The transportation system remains the same in the global level. In certain types of transportations, robots are used to fulfil existing transporting tasks. Routines remain as they are.

2. Partial reconfiguration of the system: Certain tasks are identified, and robots for these tasks are designed for optimal performance. Transportation routines are optimized based on the capabilities of robots. Existing storage facilities are utilized, and the delivery routines are stretched to 24-hour operation.

3. Restructuring of the system: In order to facilitate system wide optimization, a central stock system is implemented. Various types of materials can be stored in the central stock. The main advantage of this system is that it is possible to combine different types of materials at the central stock and send them together; so that number of dispatches is minimized. Different types of robots are introduced accordingly, and routes are optimized for 24-hour operation.
It is possible to say that most of the robot systems presented in the previous section fall into the first alternative. It is the easiest option in terms of implementation overhead; since there are minor alterations on the routines and the robot transporters are simply take place of the human counterparts wherever feasible.

Service robots in hospitals are still not very common and existing ones are under active development. Therefore it is normal to observe that they simply try to adapt to existing transportation systems. But it can also be claimed that in this alternative, the potential of using autonomous mobile robots and automation is not fully exploited.

In order to utilise the most out of an automated robotic transportation system, at least a partial reconfiguration or reconstruction is needed. It is obvious that in current case, several units are needed to be visited multiple times by different porters. Instead, supplies from sterile central, sterile production, central storage, pharmacy and the central laundry can be combined and delivered together in a single cargo unit. The incoming cargo then can be sorted out and distributed within the unit. In the same way outgoing materials can be assembled at the unit and placed in a single cargo unit. It is also possible to operate day and night to make several collections and distributions.

It is believed that, even though it is more difficult to implement compared to the first one, the second alternative is much better at taking the advantage of using mobile robots for transportation. In case of going into renovations or restructuring, existing hospitals should consider this option instead of the first one.

The third alternative is the most optimal way of designing an automated transportation system for hospitals. The aim is to restructure the whole system, and create a logistics centre instead of various decentralized storage units. In this alternative, even more emphasis can be put on 24 hour operation.

Due to the need for substantial amount of environmental modifications this alternative would require, it is not a feasible option for existing hospitals. But while new hospitals are designed, it should be the first option to consider.

The analysis also revealed that such an automated system has the potential to decrease the risk of infections. Equipment being used for transportations as well as commonly touched surfaces such as doors and elevators are sensitive places in terms of infection risk. An easy to clean robot system, as well as automated door and elevators needed for the robot operation can improve the situation.

Lastly, it should be remarked that the integration of IT technologies for ordering of supplies and planning of resources, into the transportation systems utilizing robots is another important issue that can boost the efficiency and the effectiveness. There is still a lot of room for improvement in this integration, and much progress is expected in this field. 


\section{CONCLUSION}

This paper presents the need for automated transportation systems for hospitals, gives an analysis of the existing transportation tasks based on a case study, and outlines alternative scenarios for implementation.

It is found that need for mobile robots in hospital transportation tasks is evident, but their deployment needs to be based on a thorough analysis of the whole logistics system, and their designs should be made accordingly.

While existing robotic systems show the potential of future applications, significant improvements can be made by fully or partially reconstructing the transportation frameworks.

\section{ACKNOWLEDGMENTS}

Authors would like thank Ulf Larsen and Steen Ussing, whom generously funded the survey. Authors also would like to thank Thor Hauberg and Per Boetius Andersen for their work at the hospital.

\section{REFERENCES}

[1] E. Poulin, "Benchmarking the hospital logistics process A potential cure for the ailing health care sector," CMA MANAGEMENT 77 , no. 1 (2003): 20-23.

[2] "Danmarks Statistikbank, Social conditions, health and justice, table UD2," http://www.statistikbanken.dk/UD2.

[3] "Health services - Statistics by subject, 03.02," http://www.ssb.no/english/subjects/03/02/.

[4] JF ENGLEBERGER, "Health-care robotics goes commercial: the HelpMate' experience," Robotica(Cambridge. Print) 11 (1993): 517 523.

[5] B. Graf, M. Hans, and R. D. Schraft, "Care-O-bot II-Development of a next generation robotic home assistant," Autonomous robots 16, no. 2 (2004): 193-205.

[6] F. Carreira et al., "i-Merc: A Mobile Robot to Deliver Meals inside Health Services," in Proceedings of the 2006 IEEE Internacional Conference on Cibernetics \& Intelligence Systems \& Robotics, Automation \& Mechtronics, 2006, 1-8.

[7] A.G. Ozkil et al., "Design of a robotic automation system for transportation of goods in hospitals," in Computational Intelligence in Robotics and Automation, 2007. CIRA 2007. International Symposium on, 2007, 392-397.

[8] "Aethon - TUG ${ }^{\mathrm{TM}}$ : The Automated Robotic Delivery System," http://www.aethon.com/products/logistics.php.

[9] "speciminder," http://www.ccsrobotics.com/products/speciminder.html.

[10] "Automatic Guided Vehicles for Healthcare," http://www.swisslog.com/index/hcs-index/hcs-systems/hcs-agv.htm.

[11] "AGV (Automated Guided Vehicle) Systems by FMC Technologies," http://www.fmcsgvs.com/content/products/atlis.htm. 